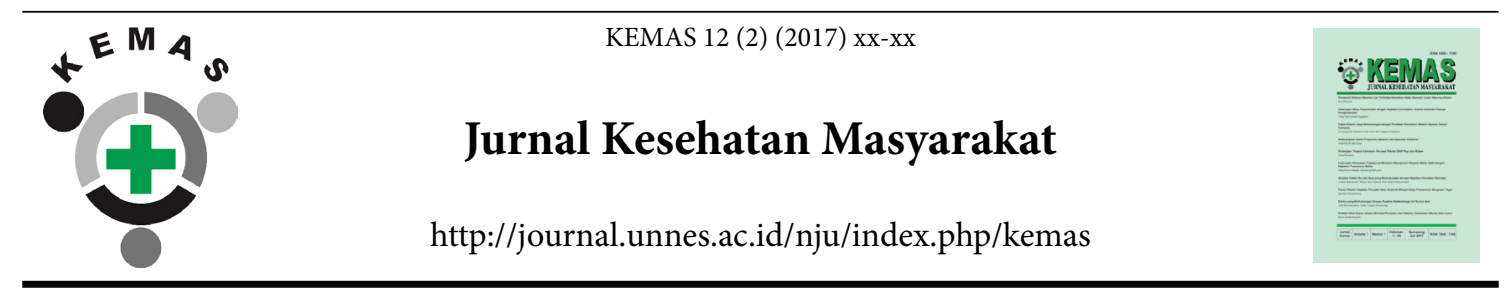

\title{
DETERMINANTS FAILURE OF EXCLUSIVE BREAST FEEDING ON HEALTH IN THE CITY BENGKULU
}

\author{
Desri Suryani ${ }^{1 \bowtie}$, Demsa Simbolon ${ }^{1}$, Nur Elly $^{2}$, B. Agustina Pratiwi ${ }^{3}$, Yandrizal $^{4}$ \\ ${ }^{1}$ Nutrition Program, Health Polytechnique of the Ministry of Health, Bengkulu \\ ${ }^{2}$ Nursing Program, Health Polytechnique of the Ministry of Health, Bengkulu \\ ${ }^{3}$ Faculty of Health Sciences, Universitas Muhammadiyah Bengkulu \\ ${ }^{4}$ Doctoral Program Student in Public Health Science, Andalas University
}

\section{Article Info \\ Article History: \\ Submitted 23 August 2016 \\ Accepted 10 November 2016 \\ Published January 2017 \\ Keywords: \\ Determinants of ex- \\ clusive breastfeed- \\ ing; Health workers \\ DOI \\ http://dx.doi.org/10.15294/ \\ kemas.v11i1.3521}

\begin{abstract}
The first 1,000 days of life program is a program to improve the quality of children in the future which one of these programs is the provision of exclusive breastfeeding. The decline in infant mortality rates slowed between 2003 to 2012 from 35 to 32 per 1,000 live births, all babies need access to key interventions such as exclusive breastfeeding. The success of these programs are driven by health workers, but the researches that analyze information about exclusive breastfeeding program on health workers, especially in Bengkulu had never been examined. The research design used mixed methods (quantitative and qualitative) on health workers in Bengkulu in 2015 who have infants aged 6-24 months ( 66 people), which were determined by purposive sampling. The results showed that $69.7 \%$ of the mothers did not practice exclusive breastfeeding and $54.5 \%$ did not practice early initiation of breastfeeding. Analysis of early initiation of breastfeeding factor as the dominant factor for failure of exclusive breastfeeding. The qualitative analysis showed confidence and perception of little milk production are factor for unsuccessful early initiation of breastfeeding .
\end{abstract}

\section{Introduction}

Infant mortality rate shows slowed trends in 2003-2012 from 35 to 32 per 1000 live births, therefore all infants may require access to key interventions such as exclusive breastfeeding. Exclusive breastfeeding could reduce the infant morbidity and mortality rate. In Indonesia, the issues are regulated in Government's Regulations Number 33 year 2012 on Exclusive Breastfeeding. According to WHO, about 220.000 infants would be saved from morbidity and mortality risk annually if they were being breastfed in their first hour of birth, and breastfed with appropriate manner until aged 2 years (WHO, 2013). Exclusive breastfeeding in the first 6 months of births have been proven as one of effective key intervention in order to reduce infant morbidity and mortality ( $\mathrm{WHO}$, 2013).

There are several reasons breastfeeding not given to infants, such as birth by caesarean section, the absence of early initiation of breastfeeding, twin birth and low birth weight (Abdullah, 2013). Beside that, employed mother, low mother education, massive formulated milk advertisement, low secretion 
of exclusive breastfeed, misperception about the need of food addition (Rahayu, 2014). Health workers in Public Health Office of Bengkulu City should have being a promotor in exclusive breastfeeding campaign, which is the facilities for breastfeeding has been provided by Health Ministry of Indonesia in 12 spot in Bengkulu City.

In Bengkulu, the provision of breastfeeding coverage based on 24 hours recall in $2015 \mathrm{had}$ reached $79.4 \%$ and has been growing in this past three years (2012-2015) to be $51.5 \%$, $78.7 \%, 81.3 \%$, and $89.1 \%$, respectively. The result of the preliminary study to three health workers in Community Health Center (Puskesmas) area indicated that there are any difficulties in giving breastfeeding, for example low secretion of exclusive breastfeed, the infant looks like they need more nutrition than just being given a breastfeeding, do not practice early initiation of breastfeeding, no lactation facilities in working place, etc. Based on those illustrations above, we aim to determine the determinants of failure of exclusive breastfeeding practice in health workers of Public Health Office of Bengkulu City of 2015. The purpose of this research is to reach an understanding of the determinants of failure of exclusive breastfeeding practice in Public Health Office of Bengkulu City.

\section{Method}

This research used mixed methods with exploratory design. Exploratory design with sequential procedure which mixed consecutively, firstly, we used qualitative methods and then, turn to quantitative methods (Creswell JW, 2006). The first phase of this research used qualitative methods with the case study approach and in-depth interview to the health workers that give exclusive breastfeeding and not give exclusive breastfeeding. In the second phase, the finding of qualitative methods, such as supports and obstacles were analyzed quantitatively to understand the determinants of unsuccessful of breastfeeding practice in health workers Public Health Office of Bengkulu City.

We selected 5 informants in in-depth interview to understand the determinants factors of the failure. The population of the research included all health workers that have infant with the age between 6-24 months in research period, which sampling method by total population method were 66 people. The relationship among research variables were analyzed by bivariate analysis with Chi square and multivariate analysis with double logistic regression.

\section{Results and Discussion}

The result of a qualitative method with case study approach concluded that factors associated mother who do not give exclusive breastfeeding for 6 month were the mother have a lot of work after three month maternity leave, low breast milk production after birth, hospital nurse give formula after cesarean section. At the same time mother who give exclusive breastfeeding because they know its benefits and realize that child who do not get exclusive breastfeeding will more likely to get sick. That was according to the answers of the following informants:

"Informant A said that she no longer give exclusive breastfeeding after three month maternity leave because she have a lot of work to do.

Informant $\mathrm{Y}$ said that actually she want to give the baby exclusive breastfeeding but after baby born she realize that she has low breast milk, so she fed the baby with formulated milk.

Informant $\mathrm{R}$, we know the definition, benefit, and rationale of exclusive breastfeeding, as well as on how to store and provide pumped milk. All information of the exclusive breastfeeding knowledge gained from college, read on the internet, books, and stories of friends.

"During childbirth on hospital X by cesarean section, after the baby is bathed, health worker immediately give formulated milk, the family seen this and prevent health worker to give that and ask to give the baby to his mother. After the baby on his mother, he is sucking directly because his mother already had breast milk and still be given exclusive breas feeding even the mother had been work. After maternity leave, informant $S$ always pump her breast milk at night for supplies during her works. Based on the experience, the first child doesn't get exclusive breastfeeding so he got 
sick easily and frequently. Informant realizes that first child was not given exclusive breastfeeding, and during the second pregnancy the informant desire to give exclusive breastfeeding to the second child. Nowadays informant D's child already 9 months old and informant Y's child is14 months old, he just got exclusive breastfeeding until 6 months old and apparently it is different, he rarely got sick (praise the Lord)."

Interviews result analysis could determine the factors that affect provision failure of the exclusive breastfeeding i.e.: the mother works so she couldn't give exclusive breastfeeding, mother couldn't give exclusive breastfeeding because her breast milk doesn't enough and give formulated milk to her child, mother works as health worker so she knows and understood about exclusive breastfeeding from college and mass media, health worker doesn't know and understand about exclusive breastfeeding so the newborn fed with formulated milk, mother pumps breast milk and store it for supply when she works, mother have experience doesn't give exclusive breastfeeding on the first child, so she want the second child to get exclusive breastfeeding.

The result of qualitative methods determined the failure factors exclusive breastfeeding at the second phase. Quantitative methods showed the frequency distribution of mother with no risk age (25-35 years old) (81.8\%), high education (95.5\%), have child $\leq$ 2 child (72.7\%), good knowledge (62.1\%), have child within $\geq 2$ years $(56.1 \%)$, didn't practice IMD (Early Initiation of Breastfeeding) (54.5\%), facilities available at the workplace $(80.3 \%)$ and do not provide exclusive breastfeeding (69.7\%). The results can be seen in Table 1:

Table 3 showed that IMD (Early Initiation of Breastfeeding) associated with exclusive breastfeeding $(p=0.026)$. Health worker who

Table 1. Frequency Distribution of Risk Factors Failure of Provision Exclusive Breastfeeding at Health Worker at Public Health Office of Bengkulu City 2015

\begin{tabular}{llll}
\hline Variable & Category & $\mathrm{n}$ & $(\%)$ \\
\hline Mother Age & Unrisk (20-35 years old) & 54 & 81,8 \\
& Risk (<20 dan >35 years old) & 12 & 18,2 \\
Education & High (D1, D3,S1, S2) & 63 & 95,5 \\
Parity & Moderate (High School) & 3 & 4,5 \\
& Primipara ( $\leq 2$ children) & 48 & 72,7 \\
Knowledge & Multipara ( $>2$ children) & 18 & 27,3 \\
& Good & 41 & 62,1 \\
Birth Gap & Less & 25 & 37,9 \\
& $\geq 2$ years & 37 & 56,1 \\
Early initiation of Breastfeeding imple- & Yes & 29 & 43,9 \\
mentation & & 30 & 45,5 \\
& No years & & \\
Husband Support & Support & 36 & 54,5 \\
Facility at work place & No Support & 34 & 51,5 \\
& Available & 32 & 48,5 \\
Provide Exclusive Breastfeeding & Not Available & 53 & 80,3 \\
& Exclusive & 13 & 19,7 \\
& No & 20 & 30,3 \\
\hline
\end{tabular}

Source: Primary Data 
Table 2. Relationship between independent variable and dependent variable

\begin{tabular}{lllll}
\hline Variable & Category & Exclusive & $\begin{array}{l}\text { Non- } \\
\text { Exclusive }\end{array}$ & $\begin{array}{l}\mathrm{p} \\
\text { value }\end{array}$ \\
\hline Mother Age & Unrisk & 29,6 & 70,4 & 1,00 \\
& Risk & 33,3 & 66,7 & \\
Education & High & 31,2 & 68,8 & 1,00 \\
Parity & Moderate & 33,3 & 66,7 & \\
& Primipara & 27,1 & 72,9 & 0,530 \\
Exclusive Breastfeeding Knowledge & Multipara & 38,9 & 61,1 & \\
\multirow{3}{*}{ Birth Gap } & Good & 24,4 & 75,6 & 0,288 \\
& Less & 40 & 60 & \\
Implementation IMD & $\geq 2$ years & 35,1 & 64,9 & 0,487 \\
& <2 years & 24,1 & 75,9 & \\
Husband Support & Yes & 43,3 & 56,7 & 0.067 \\
& No & 19,4 & 80,6 & \\
& Support & 38,2 & 61,8 & 0,239 \\
& No Support & 21,9 & 78,1 & \\
\hline
\end{tabular}

Source: Analyzed from Primary Data

implement IMD 3.661 times to give exclusive breastfeeding than those who do not implement IMD.

This study showed provision of exclusive breastfeeding on health worker in Public Health Office in Bengkulu City 30.3\% lower than the target at $2015(50 \%)$. This low rate provision of exclusive breastfeeding due to mother worry so she give formulated milk/ food. Based on interview with informants showed that someone who do not give exclusive breastfeeding because the mother was not confidence and her breast milk was not enough although the mother condition allow her to give exclusive breastfeeding. This findings is similar with research in India that found only $34 \%$ infants got breast milk until 6 month old. Exclusive breastfeeding for first 6 month is rare because only $2 \%$ infants that get 6 month breast milk only (Shifraw, 2015).
Research in Ethiopia shows that only $59.3 \%$ mother believe that exclusive breastfeeding sufficient for infants until 6 month old (Tedele, 2015). Provision breastfeeding practice has low rate for working mothers because they have less time to implement exclusive breastfeeding and there is no facility to breastfeed in the workplace (Okhia, 2015). Research in Ghana state $48 \%$ of professional workers women able to provide exclusive breastfeeding (Danso, 2014). Pathirathna 2014 in Sri Lanka state that provision of exclusive breastfeeding at housewife is higher $64.7 \%$ than workers mothers $(43.6 \%)$. This condition may caused by housewife stay longer in house since baby birth and doesn't has to feed their baby earlier like workers do (Pathirathna M.L, 2014). The other important predictor are mother doesn't confidence to breastfeed, problem to breastfeed at first week, and low knowledge

Table 3 Analysis of Multivariate Double Logistic Regression on Determinants Factors of Failure of Exclusive Breastfeeding at Health Worker at Bengkulu City

\begin{tabular}{lllll}
\hline $\begin{array}{l}\text { Analysis step } \\
\text { Step 1 }\end{array}$ & B & $P$ & OR & $95 \%$ CI \\
\hline IMD & 1,298 & 0,026 & 3,661 & $1,164-11,516$ \\
Husband Support & 0,984 & 0,095 & 2,675 & $0,843-8,490$ \\
Constant & $-2,040$ & 0,001 & 0,130 & \\
\hline
\end{tabular}

Source: Primary Data 
about breast milk (Babakazo, 2015). Lack of self-confidence led to problem at breastfeeding reflex, problem at maternal emotional disorder such as anxiety, anger, disappointment, and fear.

Most (81.8\%) of health workers in Public Health Office of Bengkulu City in 2015 aged 2035 years old. It's similar with Abdullah (2014), finding, that the majority of mother that works at Health ministry aged $20-35$ years old (91.7\%). The degeneration process of breast gland in size and regression of alveoli began at the age of 30 years. So because of that process, breast will less likely to generate breast milk. The more older age, the process mental development will improve, but at a certain age, this development will not as fast as teenager. The analysis showed there was no correlation between maternal age with provision of exclusive breastfeeding. Similar with the Smith's research, stated that there is no correlation between maternal age with provision of exclusive breastfeeding (Smith, 2013). Mother aged 25-35 years old provide exclusive breastfeeding more than who aged 15-24 years old, 8.9 times more that who aged less than 25 years old (Neji, 2015). Older mother has positive correlation with provision duration of exclusive breastfeeding. Mother aged more than 35 years old more likely to succeed providing exclusive breastfeeding (Asfaw, 2015). But, in this study there were mothers above 35 years old who did not give exclusive breastfeeding.

The results showed the majority education level of health worker was high (95.5\%), but there were still many who did not give exclusive breastfeeding. Infants who did not given exclusive breastfeeding due to health workers felt less production of breast milk and has not been smooth. The bivariate analysis showed there was no correlation between education and exclusive breastfeeding ( $p>0.05)$ (Jones, 2011). Neji (2015), research results showed that no significant relationship between the level of education and the practice of exclusive breastfeeding. The result is surprising because the research took place in higher education institutions and the majority of respondents had a higher education. More financially independent informants tend to purchase formulated milk, and also tend to do not follow the advice of their mother, husband, family, and friends or the advice of health care professionals to breastfeed their babies. This study showed mothers that are educated (high school graduation), some still do not exclusively breastfed their babies, though mothers already know the benefits of exclusive breastfeeding in formal education or electronic media / mass media. Astuti (2013), research results, there is a relationship between media exposure with exclusive breastfeeding, mothers who are exposed to media are 9.45 times more likely to exclusive breastfeeding compared with mothers who are not exposed to the media. Formulated milk advertising in the mass media influence exclusive breastfeeding especially in mothers with low education (Fikawati, 2009).

This study showed the health workers in the area of Public Health Office of Bengkulu city included in the primiparous group (72.7\%), greater than the multiparous group (27.3\%). As many as $72.9 \%$ primiparas not only don't give exclusively breastfeeding but also give formulated milk in pacifier/bottle. The results showed no association between parity with exclusive breastfeeding in health workers $(p>$ $0.05)$. This is happened despite the health workers in the city of Bengkulu have children less than 2, still there are not exclusively breastfed.

The more children are born will affect milk production as it relates to the health status of mothers and fatigue. Primiparous mothers with having the last child aged 35 years or older have the highest risk to not exclusively breastfed, the first child in a family is related to the cessation of exclusive breastfeeding (Kitano, 2016).

Knowledge on health workers are good (62.1\%), but there was health workers who had less knowledge (37.9\%). As health workers, they should have a good knowledge of being a mother, because people generally get the information about health, especially exclusive breastfeeding from health workers. This finding is supported by Abdullah (2013), in which the mothers who worked as health workers both medical and non-medical are have more knowledge than mothers who do not work. The research shows there is no correlation between having knowledge with exclusive breastfeeding 
( $p>0.05)$. It's contrast with Sriningsih study (2011), that there is a relationship between maternal education level, income level, and mothers' knowledge of breastfeeding to exclusive breastfeeding.

This study showed mother feels her milk inadequate though in fact is sufficient, when the baby sucked the breasts often cause the milk production to increase. Interviews with three informants who managed exclusively breastfed, have knowledge of exclusive breastfeeding more comprehensive.

Knowledge of the sign of inadequate breast milk is also important because many informants who add formulated milk to breast milk have reason or considers that a crying baby when it was breastfed means that the baby is still hungry and should be given another drink. The informant failed to provide exclusive breastfeeding for giving formulated milk before the baby was 6 months old. Most of failure factor were breast milk that has not been smooth after birth so the baby given formulated milk. Other factor was because mother considers breastfeeding is not enough and baby needs extra milk. In addition, there were informants that formulated milk before 6 months old because of busy working and for some reason could not give breastfeeding. Another factor contributing to not give exclusive breastfeeding was a lot of advertisement of infant formulated milk thereby affecting breastfeeding mothers in practice, because the community and nursing mothers found babies with breast milk alone is not full.

Informants who failed to give exclusive breastfeeding showed low commitment. Although almost all of the informants know the baby should only be given only breast milk until the age of 6 months and intends to provide exclusive breastfeeding, but most could not give exclusive breastfeeding. Formula-fed babies during the newborn because breast milk has not been smooth or because they feel breastfeeding is not enough. Partly because of busy work that could not express the milk.

The research found $84.1 \%$ of health workers with birth spacing $\geq 2$ years and 22 people is the first child. A total of three health workers who become informants is the first child. Mothers who gave first birth, her self- confidence is still high and quickly came to the conclusion to give formula to their babies. The research showed there was no association between birth spacing with exclusive breastfeeding ( $p>0.05)$. On Rahayu's research that birth spacing was not associated with exclusive breastfeeding (Rahayu, 2014).

Long term breastfeeding can extend birth spacing due to longer period of amenorhoe. UNICEF and WHO make recommendations on mothers to breastfeed exclusively for six months to her infants. After the age of 6 months, infants can be given complementary feeding (MP-ASI) and the mother still breastfeeding until the child is at least 2 years old. The Government of Indonesia through the Ministry of Health also recommends mothers to breastfeed exclusively for 6 months to infants.

The study showed $54.5 \%$ of mothers do not perform IMD. This was caused partly because the mother giving birth by caesarean section. Of the 66 health workers, who delivered with a specialist were 44 people $(66.7 \%)$, of which 28 people (63.6\%) had cesarean delivery, while 22 people $(33.3 \%)$ who gave birth with a midwife. Mothers who give birth vaginally 2.4 times exclusive breastfeeding than those who get caesarean section (Shifraw, 2015).

Based on interviews with informants, the causes of the failure of exclusive breastfeeding was because infants given a formulated milk shortly after birth in mothers who undergo delivery by cesarean. For infants, breastfeeding has an important role to support the growth, health and survival of infants because breast milk is rich in nutrients and antibodies. Giving other foods besides breast milk by parents shortly after birth, because the milk does not come out on the first day after birth and had to give the child other liquids such as milk formula instead of breast milk. Meanwhile there are also mothers who are too quick to give complementary foods to children so that thwart exclusive breastfeeding, this happens because of ignorance of the mother about the right age to give complementary foods for children.

Multivariate analysis showed exclusive breastfeeding failure factors exclusive in health workers in the city of Bengkulu was Early Initiation of Breastfeeding (IMD), where mothers who are conducting IMD were 3.66 
times more likely to do exclusive breastfeeding compared with mothers who do not IMD. Other studies have found a relationship between early initiation of breastfeeding with exclusive breastfeeding (Qiu, 2009). Women who undergo early initiation of breastfeeding are those who deliver vaginally. IMD is a strong enabling factor to the success of exclusive breastfeeding (Fikawati, 2010). While birth attendants who do not implement the IMD because he/she felt a rush against time. Several factors are related to the low early initiation of breastfeeding include caesarean delivery, multiple births and low birth weight (LBW) (Patel, 2015). The role of health workers / midwife in the implementation of the IMD is needed. The support provided by health care providers will generate confidence in the mother to take the decision to breastfeed (Hand, 2012). Low commitment, lack of social support and exposure before breastfeeding is a risk factor to abandon exclusive breastfeeding (Essien et al, 2013).

The results were obtained 34 votes (51.5\%) of health workers get the support of her husband. Husband provides support to mothers on exclusive breastfeeding to infants and states to support the opportunity to provide exclusive breastfeeding 2 times (Ramadani, 2010). Support or positive attitude from the couple and the family will provide its own power for the mother. In essence, the family, especially the husband should be able to work to realize the process of exclusive breastfeeding. The low support of husband makes mothers often to not eagerly breastfeed the baby. Mothers who have the support of her husband and other family members will increase breastfeeding to their babies. Less support tend to decrease breastfeeding, the practice of exclusive breast milk is associated with the couple (husband) (Nchimunya, 2015)

The results showed there was no correlation between the husband support and exclusive breastfeeding ( $\mathrm{p}$ value $=0.239$ ). This happens because the husband thought that his wife as health workers already know about exclusive breastfeeding. But there are health workers which husband are supporting to exclusive breastfeeding still do not give exclusive breastfeeding. Decision-making in exclusive breastfeeding by mothers is influenced by the support of her husband, where the husband support is integral role in the family.

Informants who managed to exclusively breastfeed their babies receive adequate support from the husband. Form of the support from the husband are searching and reading information about exclusive breastfeeding, encouraging informants to remain exclusive breastfeeding, there is also the mother of informants who give formulated milk when breast milk has not come out smoothly on the first day until the third day after childbirth because they feel sorry for the baby can't be breastfed sufficient. In addition, the husband approves formulated milk before 6 months of age because of a reason breastfeeding breast milk has not been smooth or felt less breast milk production. Therefore, knowledge of exclusive breastfeeding is not only given to nursing mothers but also to her family members, especially her husband.

The results showed there was no correlation between workplace facilities with exclusive breastfeeding ( $p>0.05)$. This study is not consistent with Abdullah (2013), research that found a correlation between the availability of facilities with exclusive breastfeeding.

Informants who successfully breastfed exclusively had the support of the workplace, especially the support from superiors to allow expressing milk between working time and to allow return briefly to breastfeed their babies which house are close to the health center.

Informants who failed to provide exclusive breastfeeding have house that far from workplace while in office no room lactation. There was an informant who succeeded in exclusive breastfeeding until the baby is 4 months old, but later disconnected because at home could not express milk before work and in the office have no room to express milk, resulting from the age of 4 months, babies are formulated milk

Low exclusive breastfeeding practice on health workers because lack of confidence and need support from the husband, it is required effort to increase husband's knowledge about exclusive breastfeeding by inviting the husband to join the Antenatal Care (ANC) and give an explanation of exclusive breastfeeding. The failure of exclusive breastfeeding need firmness of the implementation of Government 
Regulation No. 33 Year 2012 on Provision of Exclusive Breastfeeding, that health workers and health care provider's facilities are required to conduct early initiation of breastfeeding to new born baby for a minimum of 1 (one) hour, giving information and education of exclusive breastfeeding to the mother and / or family members of the baby starts from antenatal care until the period of exclusive breastfeeding is completed. Health workers are prohibited from providing formulated milk and/or other baby products which can hamper the program of exclusive breastfeeding. Workplace administrator and organizer of public facilities should provide particular facilities for breastfeeding and/or expressing milk in accordance with the conditions of the company's ability

\section{Conclusion}

The coverage of exclusive breastfeeding in health workers in the city of Bengkulu is still low, because they feel less confidence that breast milk will be sufficient to meet the nutritional needs of infants, therefore they give formulated milk. Factors that contribute in failure of exclusive breastfeeding in health workers in the city of Bengkulu need firmness of implementation on Government Regulation No. 33 Year 2012 on Provision of Exclusive Breastfeeding. Management of lactation should be done by the midwife during the antenatal care (ANC).

\section{Acknowledgement}

Our thanks to the Agency for Development and Empowerment of Health Human Resources (BPPSDM) Health that facilitates our research funding, Chief Medical Officer and its Chief of Community Health Centers in Bengkulu city who gave permission for research. Colleagues who are willing to be sampled as well as the Executive Power of Nutrition who helped conduct the study.

\section{References}

Abdullah, G.I, Ayubi, D.2013. Determinan Pemberian ASI Ekslusif pada ibu pekerja. Jurnal Kesehatan Masyarakat Nasional, 7(7):298-303.

Asfaw MM., Argaw, M.D., Kefene, Z.K.2015. Factors associated with exclusive breastfeeding practices in Debre Berhan District, Central Ethiopia: a cross sectional community based study. International Breastfeeding Journal.; 10
(23):1-9. DOI 10.1186/s13006-015-0049-2

Babakazo, P. Donnen, P., Akilimali P., Ali, N.P.A. 2015. Predictor of discontinuing exclusive breasfeeding before six month among mothers in Khinshasa:a prospective study. International breasfeeding journal, 10(19):118

Cameron, R.A. 2009. A. Sequential mixed model research design: design, analytical and display issues. International Journal of Multiple Research Approaches, 3(2):1-15

Danso, J. 2014. Examining the Practice of Exclusive Breastfeeding among Professional Working Mothers in Kumasi Metropolis of Ghana. International Journal of Nursing, 1(1):11-24.

Essien, N.C., Samson-Akpan, P.E. 2013. Factors influencing the practice of exclusive breasfeeding among women in Ikot Omin, Calabar, Nigeria, Mary Slessor. Journal of Medicine, 2(1):51-63

Fikawati, S., Syafiq, A. 2003. Hubungan antara Immediate Breastfeeding dan ASI eksklusif 4 bulan. Jurnal Kedokteran Trisakti, 22(2): 47-55.

Handayani, L, Kosnin A.M., Jiar Y.K. 2012. Breastfeeding Education in Term of Knowledge and Attitude through Mother Support Group. Journal of Education and Learning, 6 (1): 65-72

Jones, J.R., et. al. 2011. Factors Associated With Exclusive Breastfeeding in the United States. Pediatrics, 128(6):1117-1125.

Kitano. N., et. al. 2016 Combined effects of maternal age and parity on successful initiation of exclusive breastfeeding. Preventive Medicine Reports, 3:121-126.

Neji, O,I, Nkemdilim, C.C., Ferdinand N.F. 2015. Factors influencing the practice of exclusive breastfeeding among mothers in tertiary health facility in Calabar, Cross River State, Nigeria. American Journal of Nursing Science, 4(1): 16-21

Nchimunya C., et. al. 2015. Factors affecting the adoption of exclusive breasfeeding by mothers in Chelstone, Lusaka. International Invention. Journal of Medicine and Medical Science, 2(5):73-79.

Okhia O, et. al. (2015). Level of acceptance and practice of exclusive breastfeeding: A case study of working class mothers in the nursing service in Irrua specialist teaching hospital, Nigeria. International Journal of Nursing and Health Science, 2(1): 8-12.

Pathirathna ML. 2014. Exclusive breast feeding practice in gangawatakoralaya $\mathrm{MOH}$ area, Sri Lanka. International Journal of Scientific 
and Research Publications, 4( 2):1-3.

Qiu L., Zhao Y., Binns CW., Lee AH., Xie X. 2009. Initiation of breasfeeding and prevalence of exclusive breasfeeding at hospital discharge in urban, sub urban and rural areas of Zhejiang China. International Breasfeeding Journal, 4(1):1-7.

Rahayu S., Apriningrum, N. 2010. Faktor-faktor yang Berhubungan Pemberian ASI Eksklusif Pada Karyawati UNISKA 2013. Jurnal Ilmiah Solusi,1(1):55-63.

Ramadani M., Hadi EN. 2010. Dukungan suami dalam pemberian ASI eksklusif di Wilayah Kerja Puskesmas Air Tawar Kota Padang, Sumatera Barat. Jurnal Kesehatan Masyarakat Nasional, 4 (6): 269-274.

Smith J.P., et. al. 2013 Workplace Support, Breasfeeding and health. Family Mother, 93:58-73.

Shifraw T., Worku A, Berhane Y. 2015. Factors associated exclusive breastfeeding practices of urban women in Addis Ababa public health centers, Ethiopia: a cross sectional study. International Breastfeeding Journal, 10(22) :1-6.

Sriningsih, I. 2011. Faktor Demografi, Pengetahuan Ibu Tentang Air Susu Ibu dan Pemberian ASI Eksklusif. Jurnal Kemas, 6 (2):100-106

Tedele N., Habta F., Akmel D., Deges E. 2015. Knowledge, attitude and practice towards exclusive breastfeeding among lactating mothers in Mizan Aman town, Southwestern Ethiopia: descriptive cross-sectional study. International Breasfeeding Journal, 11(3):1-7

WHO. 2013.Cause-Specific Mortality Estimates for Major Causes of Child Death for 2000-2013. World Health Organization and Child Health Epidemiology 